\title{
El deslizamiento de la identidad: entre política y subjetividad
}

\author{
Griselda Gutiérrez Castañeda
}

\begin{abstract}
Aun en los tiempos más oscuros tenemos el derecho a esperar cierta iluminación, y que dicha iluminación puede provenir menos de las teorías y conceptos que de la luz incierta, titilante y a menudo débil que algunos hombres y mujeres reflejarán en sus trabajos y sus vidas bajo casi cualquier circunstancia y sobre la época que les tocó vivir en la tierra.
\end{abstract}

Hannah Arendt

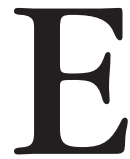

vocar las palabras de Hannah Arendt en Hombres en tiempos de oscuridad parece del todo pertinente con el propósito de reflexionar sobre las "representaciones fílmicas de problemas identitarios", ${ }^{1}$ es oportuno porque la problemática que registra el documental Trazando Aleida. La historia de una búsqueda ${ }^{2}$ que intentaré analizar, nos habla de los tiempos de oscuridad que en la historia de México se repiten hasta la náusea, pero que en este caso nos remiten al episodio de la guerra sucia de los años setentas, oportuno porque la luz incierta, titilante y a menudo débil de Aleida Gallangos Vargas, víctima de la desaparición forzada de sus padres, no le quita fuerza para reivindicar su derecho a esperar cierta iluminación, y porque es precisamente a través de un ejercicio cinematográfico en el género del documental - género tan vivo, tan indispensable hoy día-, que se encienden las luces y las cámaras para procurarnos cierta iluminación.

Se trata del encuadre de una compleja historia colectiva silenciada por la censura, por la represión, por la tortura y la muerte, un encuadre que tan sólo alude a través de fragmentos a la persecución, la intolerancia, la desaparición forzada, que elude la historia de pobreza endémica e injusticia que impulsa

${ }^{1}$ Ése fue el título del Primer Encuentro de Cine y Filosofía, en diciembre de 2012, organizado por los proyectos de investigación "Democracia y territorio: construcción de identidades", UNAM, FFL, y "Problemas filosóficos en el concepto de interpretación: aspectos epistémicos y lingüísticos", Universidad Nacional de Comahue, Argentina.

${ }^{2}$ Trazando Aleida. La historia de una búsqueda. Documental de Christiane Burkhard, México. 
las luchas guerrilleras, la política de tierra quemada, ${ }^{3}$ el aniquilamiento de comunidades enteras y la devastación de sus territorios, o la tortura en "las celdas llamadas 'el infierno'” - prácticas de las que nos da cuenta Carlos Montemayor en su magistral novela Guerra en el paraíso-, ${ }^{4}$ y este documental no los aborda, a diferencia de la prolija y documentada reconstrucción que Montemayor realiza de estos aspectos en su novela política, porque la directora del film Christiane Burkhard opta por la estrategia de proyectar luces de manera indirecta al contexto político, a través de la iluminación de las profundidades de la tragedia humana condensadas en la persona de Aleida.

Aleida puede ser el personaje deseado por todo cineasta porque encierra toda la fuerza y complejidad que puede llenar una historia, un guion, una pantalla, cuyo impulso vital puede proyectar sentido a los personajes que la rodean y al sinsentido del autoritarismo y la "violencia institucional". Pero lejos de ser tan sólo el personaje, Aleida y su búsqueda de las raíces que fueron arrasadas por las llamas de la "tierra quemada", se vuelven la ocasión para compartir la experiencia de esa búsqueda por parte de la directora, una línea de acción que puede ser muy frecuente en el género documental, un compenetrarse no con personajes ficticios, sino con personas de cuya contundente y conmovedora experiencia parece difícil tomar distancia. Todo lo cual, cuando así ocurre, puede, al menos en parte, explicar que como espectadores no podamos más que involucrarnos, y vivir a la par de Aleida la ilusión de dar con el paradero del hermano del que fue separada cuando son detenidos y desaparecidos sus padres, la angustia y ansiedad por el encuentro con su hermano Lucio, el desasosiego del desencuentro con Juan Carlos Hernández - nombre con el que lo registraron sus padres adoptivos-, quien ignora ese pasado y todo vínculo con la familia Gallangos Vargas.

Pero resulta ser que Trazando Aleida. La historia de una búsqueda, es además el ejemplo perfecto para reflexionar sobre los problemas identitarios, no tan sólo porque nos remita a la incompletud constitutiva de la identidad, a su condición fisurada, porque además nos permite detenernos en la radicalidad de estas tesis al confluir la lógica de los procesos de la subjetivación con la lógica de la política y de lo político. ${ }^{5}$

${ }^{3}$ La estrategia militar de tierra quemada o tierra arrasada, que tiene una larga historia, fue reactualizada y ampliamente utilizada en el combate a los movimientos guerrilleros en México y Centroamérica, con el propósito de bloquearles no sólo todo abastecimiento, sino además todo respaldo social por parte de las comunidades rurales. Una estrategia predatoria que destruyó territorios y en proporciones incalculables la vida de la población civil.

${ }^{4}$ Carlos Montemayor, Guerra en el paraíso. México, Seix Barral, 1991.

${ }^{5}$ Desde la perspectiva lacaniana se da cuenta de la falta como condición constitutiva de la subjetividad, esa incompletud que nos remite a un proceso identitario abierto, 
Trazando Aleida es, al decir de su protagonista, un intento por reconstruir su historia; pareciera entonces que el recurso a aplicar es la reconstrucción testimonial, en la que se trabaja con los fragmentos de la experiencia vivida ya como víctima de la tortura, de la persecución o, en su caso, mediante los avatares de la lucha por sobrevivir al exterminio, pero en el caso de Aleida como en el de Lucio no hay ocasión para el testimonio, su corta edad, dos y cuatro años respectivamente, les imposibilita haber sido testigos de la violenta detención de sus padres y de su propia orfandad.

Los retos no pueden ser mayores, en este caso se trata de La historia de una búsqueda, una búsqueda que Aleida no puede compartir con Juan Carlos, quien se siente vulnerado por los hallazgos de Aleida: como el que son hermanos, que ella no es Luz Elba Gorostiola, nombre con el que fue registrada por sus padres adoptivos, que él tampoco es quien supone sino Lucio, que son hijos de Carmen Vargas y Roberto Antonio Gallangos, que son hijos de desaparecidos políticos en su calidad de miembros de la Liga 23 de Septiembre, ${ }^{6}$ que fueron separados y trastocadas sus vidas, que tienen una abuela paterna, Quirina Cruz, quien no ha cesado a lo largo de treinta años de reclamar que le devuelvan vivos a sus hijos y dar con el paradero de sus nietos.

La búsqueda de Aleida no puede apelar a la memoria, a su memoria, tiene que retomar los fragmentos de la de otros, los de la abuela recién encontrada, apelar a la imagen de las fotografías familiares, a las de los archivos oficiales que captan la imagen del padre con huellas de tortura en una de las detenciones de que fue objeto, atenerse a pequeños indicios, fragmentos, líneas de conexión e imágenes truncadas, como el documento quemado del certificado de estudios de su madre. Una experiencia con lagunas de sentido, como la que le declara el hermano al mirar esas imágenes, quien no cuenta con recursos para interpretar las expresiones, las actitudes de los que allí aparecen; lo que ambos constatan es la desaparición, el desgarre, el vacío.

En un horizonte arendtiano se considera que la construcción de la memoria puede ser la vía que ilumine nuestro presente, porque nos permite pensar en comunidad con los otros, porque armar la narración por vía del diálogo entre autor y testigo trasciende la singularidad de la experiencia y se integra a la pluralidad, es un acto público que mediante la palabra, mediante el discurso

y nunca cabalmente cumplido. Esta tesis será capitalizada para dar cuenta de la lógica contingente en que se juega lo político y la política; es una propuesta teórica desarrollada por Laclau y Mouffe, que permite la comprensión del carácter precario, conflictivo y abierto de lo social, de la política y de la subjetividad misma,

${ }^{6} \mathrm{El}$ antecedente de su creación son las luchas guerrilleras de los años sesentas y setentas con destacados líderes como Genaro Vázquez y Lucio Cabañas, entre otros. La Liga 23 de Septiembre -fecha que evoca el levantamiento en Ciudad Madera, Chihuahuase funda el 15 de marzo de 1973 y es combatida y desmantelada en agosto de 1976. 
y la memoria transmite una experiencia, articula un espacio público que nos permite reconstruir y juzgar.

Tesis con la que no podemos más que estar de acuerdo, con este documental se publicita un expediente de nuestra historia que ha sido confiscado al gran público, y nos da elementos para juzgar la ignominia y sus secuelas en la vida concreta de las personas.

Sin embargo, más allá de condiciones ideales de diálogo, a lo que se nos enfrenta es a los obstáculos insalvables para pensar en comunidad con los otros. En efecto, pareciera un desliz, un error, que Aleida manifieste que su propósito es reconstruir su historia y no así su memoria, pero es un acierto inequívoco, los perpetradores de la desaparición de sus padres son, como diría Vidal-Naquet, "asesinos de la memoria", ni a ella ni a su hermano les dieron ocasión, aun como víctimas, de reconstruir una memoria.

En palabras del autor en pugna con los historiadores revisionistas pro nazis declara:

Como historiador sé, tanto como cualquiera, que la memoria no es la historia, y no es que esta última suceda a la primera por vaya a saber qué automatismo, sino porque el modo de selección de la historia funciona de otra manera que el modo de selección de la memoria o del olvido. Entre la memoria y la historia puede haber tensión, y hasta oposición. Pero una historia del crimen nazi que no integrase la memoria, sería una historia muy pobre. Los asesinos de la memoria han elegido bien su objetivo: quieren golpear a una comunidad sobre las mil fibras aún dolorosas que la ligan a su propio pasado. ${ }^{7}$

Si de suyo la construcción de la identidad está cruzada por la metabolización imaginaria de ordenamientos que le trascienden y a la vez le constituyen, si la propia identidad se sustenta en la memoria -al decir de Arendt, en su interpretación del potencial ético-político de la memoria-, la encrucijada de Aleida no puede menos que enfrentarnos a la radicalidad de la teoría especular de la subjetividad, su alternativa es la reconstrucción inventada en sentido lato, la reconstrucción sin memoria. ${ }^{8}$ La pregunta no es solamente qué se hace cuando rearmar la memoria está marcada por la imposibilidad, eso que histórica y políticamente es un reto, a la vez que un "deber de memoria", como sostiene

${ }^{7}$ Pierre Vidal-Naquet, Los asesinos de la memoria. México, Siglo XXI, 1994, p. 14.

${ }^{8}$ Ciertamente, en la interpretación lacaniana de la fase del espejo se explica el carácter especular, ficcional, del proceso imaginario configurador de la subjetividad, pero cuya calidad ficcional pasa inadvertida para el sujeto. Sin embargo, el caso que nos ocupa da cuenta de un trastocamiento de los términos, en tanto la reconstrucción de una identidad transita a través de un ejercicio intencionado. 
Primo Levi, en este caso es un desafío aún mayor, y a la vez una constatación contundente del carácter frágil, fútil, fisurado de la subjetividad.

Aleida confiesa que el propósito que la mueve al buscar al hermano y al utilizar la plataforma del documental es "recuperar la historia de la familia" que se cruza con "la historia de todos", que es "una historia que tiene muchos comienzos", una "historia que hay que armar". En efecto, una historia que registra datos en archivos documentales, hasta hace muy poco reservados para el uso de la policía política, y en escasa proporción abiertos a consulta, en calidad de archivos mutilados. Fichas que registran los nombres de los padres, su participación en agrupaciones subversivas, fechas, lugares, la clasificación de sus delitos.

Pero en esa reconstrucción de la historia/memoria en clave subjetiva, en su calidad de no-testigo la pregunta es: en esa historia, en esos documentos ¿dónde se contienen, dónde se registran las motivaciones, el impulso, las convicciones, las ilusiones de que otro mundo sea posible? Eso, es parte de lo que les fue arrebatado a Aleida y a Lucio, lo que encuentran son datos, girones.

Arendt junto con tantos otros, en calidad de víctimas sobrevivientes, de familiares de víctimas, de historiadores, de filósofos, pugnan por el potencial del género de la memoria, por ser una vía -como lo he suscrito en otra parte

[...] que no sólo actualiza nuestra intersubjetividad, sino una acción pública en la que se juega con el material de los acontecimientos, del tiempo y de la intencionalidad, de acontecimientos que más allá de lo casual y sin propósito nos sitúa a los seres humanos frente a nuestras acciones, acciones que de manera irrevocable nos confrontan con la realidad, la que muchas veces nos muestra su faz más terrible y difícil de soportar, como es la barbarie del genocidio y la perversidad de los métodos totalitarios [como de los de toda suerte de autoritarismo]. Afirmar el presente y las posibilidades de futuro implica el ejercicio de la memoria, descifrar su trama y articulación ineludible con el pasado, pero qué ardua tarea cuando afirmar la vida, darle sentido y posibilidad implica reconstruir un pasado de muerte y destrucción, un tránsito por el sinsentido.

Es por ello que el ejercicio de memoria que reconstruye acontecimientos semejantes patentiza como ninguno la intencionalidad de tal acontecer, como de aquellos o aquellas que rescatan de la disolución, del anonimato y del olvido, la voz y la experiencia de los que perecieron ante tal secuela de destrucción, de los que padecieron y sobrevivieron a la misma, y a la vez rescatan del anonimato y la impunidad a quienes como artífices o cómplices hicieron posible la barbarie, es pues un ejercicio que nos confronta a la responsabilidad de nuestras acciones, 
la de asumir las consecuencias de los propios actos, la de no guardar silencio, y la responsabilidad de hacernos cargo de nuestra historia. ${ }^{9}$

El documental en cuestión, que insisto es hoy un género tan potente, tiene el tino de procurar descifrar la trama con ese pasado de destrucción e impunidad sin recurrir al recuento histórico y puntual de los hechos, porque como diría Vidal-Naquet resultaría una "historia muy pobre", no puede apelar a la memoria porque Aleida, como Lucio, han sido privados de la misma, la virtud del documental es intentar cumplir con ese "deber de memoria", haciéndonos, como espectadores, compartir y participar en esa tarea colectiva de búsqueda, de construcción de trazos de una memoria, pero lo hace condensando dicho propósito con un hecho incontestable, enfrentarnos a la vez al cariz endeble y carente de esos trazos, el recurso es haciéndonos partícipes de las vivencias, las expectativas, la frustración, la falta, el punto de cruce entre una historia y una memoria imposible, el punto de cruce de la subjetividad.

La intensidad de esta experiencia compartida al mismo tiempo nos asoma a lo que representa el fracaso del procesamiento de los conflictos, de la metabolización política de éstos, confrontándonos así con la radicalidad de lo político desde donde se instituye al amigo o al enemigo, desde donde el antagonismo borra y aniquila vidas, trayectorias, proyectos, vínculos.

Indirectamente nos lleva a reflexionar sobre la gran pugna que se vive hoy sobre el recuerdo y el olvido en el ámbito público en aquellos países que han sufrido golpes militares, y desaparición forzada de la oposición como estrategia sistémica, e inevitablemente a reflexionar sobre cómo en el México de "la dictadura perfecta" ni siquiera ha habido ocasión para un debate semejante. Episodios como la guerra sucia son una historia inexistente, escamoteada si no es que negada oficialmente, y lo peor, socialmente eludida, no hay lugar para la construcción de la memoria como acto colectivo, sea porque se ignora, o porque si hay indicios se borran por incómodos, por perturbadores. Esa negación oficial de los hechos va a la par con una sociedad anómica, incapaz de ser el sostén que haga resonar la lucha aislada, solitaria, de quienes en calidad de víctimas pugnan por justicia.

Si contrastamos experiencias, podemos constatar que incluso en el caso de las madres integrantes de organizaciones de denuncia de sus hijos desaparecidos, existen al menos horizontes de referencia, afectos, recuerdos que sustentan la identidad de sus familiares, en la búsqueda de Aleida lo que hay es orfandad, como plasmación de la falta, hay ausencia, vacío, tan sólo cuenta con la voluntad de invención, de ahí la febril búsqueda del hermano, el

${ }^{9}$ Griselda Gutiérrez Castañeda, "Los retos de la memoria", en B. Alcubierre et al., coords., Oralidad y escritura. Trazas y trazos. México, Itaca/UAEM, 2011, p. 37. 
deseo de concretar el hallazgo como posibilidad de descubrir el vínculo que le contenga, de ahí la contundencia del desencuentro, de la búsqueda fallida.

Se puede afirmar que en el periplo que la lleva de Ciudad Juárez a Oaxaca para conocer a la abuela, de México a Washington en la localización del hermano, de la búsqueda de apoyo institucional, a la vinculación con redes sociales, con medios, con la propia documentalista o con migrantes con los que circunstancialmente se topa, lo que encuentra es el dolor de la abuela, la solidaridad de quienes ajenos a su vida la acompañan en su aventura, la simulación y falta de apoyo institucional, ${ }^{10}$ y el desencuentro con el hermano.

Esta experiencia que de inicio la lleva a transmitir la emoción ante la cámara al dar con el paradero de éste y poder comunicarle "traigo mi trabajo y mi ilusión por conocerte", muy pronto refleja la imagen pura del desconsuelo al constatar que sus expectativas tienen por único sustento trozos de historia, únicos asideros para continuar con la faena de construir algo que no existe, su vínculo filial, su propia identidad.

Cuando la ficha técnica da cuenta del contenido del documental se dice que es la experiencia de los hermanos -víctimas de la guerra sucia-, que se "reencuentran y recuperan su identidad original", ${ }^{11}$ un desacierto que nos habla de la necesidad subjetiva de un punto arquimédico que nos sostenga. El contenido del documental lo que nos muestra no es una identidad original sino su imposibilidad, el propio ánimo de Aleida que le contagia a algunos de los que circunstancialmente la acompañan es descubrir el punto donde "comenzó todo", el vínculo que se perdió pero que en algún lugar debe de estar, y que no podrá menos que sostener la alegría del hallazgo.

Con lo que se encuentra es que las relaciones que constituyen a la identidad, en su caso no existen, al caminar al lado del hermano y experimentar que tales relaciones no se pueden inventar, que todo está por construirse. Que incluso sus nombres, Aleida en memoria del Che,${ }^{12}$ Lucio en memoria del líder guerrillero Lucio Cabañas, son condensaciones simbólicas que dan cuenta de otras historias, ajenidad que se acentúa dada su carencia de referentes, su falta de lazos primordiales.

Al cabo, la tesis del cariz fisurado de la subjetividad que filósofos y analistas solemos festinar tanto por el potencial que encierra, como el carácter no fijo,

${ }^{10}$ Uno de los recursos a que acude Aleida Gallangos es a la Fiscalía Especial para Movimientos Sociales y Políticos del Pasado, organismo creado durante la gestión de Vicente Fox como Comisión de la Verdad, cuyo trabajo fue al cabo cuestionado. El apoyo que se le brindó fue escaso y falto de compromiso, no obstante lo cual dicho organismo se acredita en forma mendaz el reencuentro de los hermanos Gallangos como uno de sus logros.

${ }^{11}$ Las cursivas son nuestras.

${ }^{12}$ Aleida es el nombre de la hija del líder guerrillero Che Guevara. 
la incompletud de la identidad, las posibilidades de resignificación, más allá de la teoría se objetiva cuando el ímpetu de Aleida enfrenta la vivencia con toda la crudeza y radicalidad, y declara "me voy dibujando a mí misma".

Ciertamente, son trazos que nos muestran cómo el deslizamiento de la identidad además de remitir a algo que no es fijo sino que corre a través de vías asociativas, puede también fracasar, o hacer mayormente arduas esas articulaciones por efecto de la violencia. 